V.

Aus dem Laboratorium der hydrotherapeutischen Anstalt der Universität Berlin.

\title{
Ueber die Wirkung der Borsäure auf einige Bakterien der sogenannten Fleisch- und Wurstvergiftungen.
}

Von

Oberstabsarzt z. D. Dr. R. Bassenge.

Von Seiten der Gegner und Anhänger der Nahrungsmittel-Conservirung vermittels Borsäure werden dauernd neue Argumente aus den verschiedensten Versuchsanordnungen beigebracht, um entweder die Schädlichkeit oder die Unschädlichkeit der Borsäure auf den menschlichen und thierischen Organismus zu erweisen. Das letzte Wort in dieser Streitfrage hat zunächst noch Liebreich ${ }^{1}$ ) behalten, welcher durch Schwitzversuche an Studenten nachgewiesen hat, dass ein nicht unbeträchtlicher Theil der dem Menschen einverleibten Borsäure durch die Schwcissdrüsen entleert wird, welche so gewissermaassen für die Nierensecretion eintreten.

Während nun die Frage der Schädlichkeit der Borsäure für den menschlichen Körper heiss umstritten ist, scheint der Nutzen der Borsäure für die Conservirung von Nahrungsmitteln, insbesondere von animalischen wie Fleisch und Wurst, allseitig anerkannt zu sein, indem auch von den Gegnern als feststehend anerkannt wird, dass genügend grosse Mengen von Borsäure in Fleisch und Fleischconserven die stinkende Fäulniss und offenkundige Zersetzung des Fleisches zu verhindern oder hinauszuschieben im Stande sind. Wenn der Borsäure diese fäulnissverhindernden Eigenschaften nicht zukämen, würde sie sich weder der Empfehlung Liebreichs²) im Reichs-Medizinal-Kalender als Conservirungsmittel für Milch und Fleisch noch der fortdauernden um-

1) O. Liebreich, Ueber die Ausscheidung der Borsäure beim Menschen durch den Schweiss. Therap. Monatshefte. August 1904.

2) 0. Liebreich, Anwendung, Dosirung und Arzneiform der gebräuchlichen, der neu eingeführten und der in dem Arzneibuch für das deutsche Reich (Pharmacopoea Germanica ed. IV) 1900 enthaitenen Heilmittel. Reichs-Medicinal-Kalender. 1905. I. Th. S. 3. 
fangreichen Verwendung Seitens der Fleischconserven-Fabrikanten zu erfreuen haben.

Die entwickelungshemmenden Eigenschaften der Borsäure auf Fäulnissbacterien in Fleischconserven sind somit durch jahrelange Erfahrungen empirisch bestätigt. Systematische Untersuchungen über die keimtödtenden und entwickelungshemmenden Eigenschaften der Borsäure auf Fäulnissbacterien sind meines Wissens noch nicht angestellt worden, sie erübrigen sich ja auch, da diese Eigensehaft in Deutschland praktisch nur für Nahrungsmittelfälscher in Betracht kommt, nachdem der Bundesrath laut Bekanntmachung des Reichskanzler's rom 18. Februar 1902 ${ }^{1}$ ) bestimmt hat, dass Borsäure bei der gewerbsmässigen Zubereitung von Fleisch nicht mehr angewendet werden darf.

Merkwürdiger und bezeichnender Weise existiren keine Untersuehungen darüber, ob der Zusatz von Borsäure zu Fleiseheonserven nicht nur die Fäulnissbacterien an der Entwickelung hindert, sondern ob or auch diejenigen Bacterien unschädlich macht, welche für die Entstehung der so ausserordentlich gefürchteten und durch Massenerkrankungen Aufsehen erregenden Fleisch- und Wurstvergiftungen verantwortlich zu machen sind. Von einem Nutzen der Borsäure für die Fleischconscrvirung wäre man vom Standpunkt des Arztes erst dann zu sprechen berechtigt, wenn Borsäurezusatz zu Fleischconserven auch diese gefährlichen Fleisch- und Wurstgift-Bacterien mit Sicherheit vernichtete, während der Schlächter nur das Interesse hat, dass durch Entwickelungshemmung der Fäulnissbacterien mittels Borsäure scine Waare marktfähig blejbt.

Für die nachfolgend mitgetheilten Versuche standen zur Verfügung 1. Culturen von Bac. botulinus, 2. zwei verschiedene von van Ermengem gezuchtete Fleischvorgiftungsbacillen, 3. ein von B. Fischer-Kiel gelegentlich einer Massenerkrankung isolirter, als Enteritis-Futterkamp bezeichneter Bacillus. Dann erschien es auch nicht unwichtig, die U'ntersuchungen über dic Einwirkungen der Borsäure auch auf andere Krankheitserreger, welche als Fintrittspforte in den menschlichen Körper den Digestionstractus haben, auszudehnen, nämlich auf den Gaffky-Eberthschen Bacillus und auf Bacterium coli.

Versuchsanordnung: Abgemessene Mengen alkalischer Bouillon wurden mit $1 / 2-1-2,5$ und 5 pCt. Borsäure versetzt und diese in Dampftopf gut gelöst. Diese Borsïure-Bouillonröhrchen wurden mit gleichen Mengen (eine Oese 24 stündiger Bouilloncultur) von Bac. van Ermengem-A ertr y ck, Bac. van Ermengem-Willebroek, Bac. enteritidis-Futterkamp (Bernh. Fischer), Bac. Gaffky-Eberth und Bacter. coli beschickt; dazu wurden die nöthigen Controlen angelegt. Nach 24 stündigem Aufenthalt im Brutschrank wurden sämmtliche Röhrchen, auch diejenigen, welche makroskopisch und mikroskopisch keine Spuren von Wachsthum zeigten, bakteriologisch durch reichliche Aussaaton auf andere Nährböden (Bouillon und Agarplatten) weiter verarbeitet. Das Lndresultat ergiebt sich aus nachstehender Uebersicht:

1) Reichs-Gesetz-Blatt. 1902. S. 48. 
I. Entwickelungshemmung bei Aussat in Borsäure-Bouillon.

\begin{tabular}{|c|c|c|c|c|c|}
\hline \multirow{2}{*}{ No. } & \multirow{2}{*}{ Verwendete Mikroorganismen } & \multicolumn{4}{|c|}{ Borsäure-Zusatz } \\
\hline & & $5 \mathrm{pCt}$. & $2,5 \mathrm{pCt}$ & 1 pCt. & $1 / 2 \mathrm{pCt}$. \\
\hline 1. & Bac. van Ermengem-Aertryck & $t$ & $+\dagger$ & $+t$ & $+t+$ \\
\hline 2. & Bac. van Ermongem-Willebrock & $\dagger$ & $+t$ & +1 & +1 \\
\hline 3. & $\begin{array}{l}\text { Bac. enteritidis-Futterkamp } \\
\text { (Bernh. Fischer-Kiel). }\end{array}$ & 0 & $\dagger$ & $+t$ & $+t+$ \\
\hline 4. & Bac. Gaffky-Eberth . & 0 & 0 & +1 & +1 \\
\hline 5. & Bacterium coli . . . . . & 0 & 0 & $+t$ & \\
\hline
\end{tabular}

tt Reichliche Entwickclung (entsprechend der Entwickelung in der Controle).

†† Mässige Entwickelung.

+ Noch erkennbare deutliche Entwickelung.

0 Vollständige Entwickelungshemmung.

Die Wiederholung der Versuche führte zu demselben Ergebniss, so dass sich daraus ergiebt, dass eine 1/2 proc. Borsäurelösung auf die Entwickelung der zur Untersuchung verwendeten Bacterien keinen, eine 1 proc. Lösung einen nur geringen Einfluss ausübt. Selbst 5 proc. Lösung vermochte die Entwickelung der van Ermengem'schen Bacillen nicht gänzlich zu unterdrücken, wïhrend Bacillus enteritidis Futterkamp, Bacillus Gaffky-Eberth und Bacterium coli in ihrer Entwickelung vollständig gehemmt wurden.

In einer zweiten Reihe von Versuchen sollte des Weiteren festgestellt werden, $a b$ und welche Borsäuremengen genügen, um die zu den Versuchen benutzten Bacterien in Culturen abzutödten. Die Versuche wurden demgemäss in der Weise angestellt, dass die Borsäure den gut gewachsenen 24 stündigen Culturen der betreffenden Bacterienarten zugesetzt wurde. Nach ein- bis sechstägiger Einwirkung der Borsäure auf die Culturen im Brutschrank wurden Proben der Culturen anf Agarplatten ausgesät. Das Endresultat ergiebt sich aus nachstehender Uebersicht:

II. Abtödtung von Bakterien-Culturen durch Borsäure.

\begin{tabular}{|c|c|c|c|c|c|}
\hline \multirow{2}{*}{ No. } & \multirow{2}{*}{ Verwendete Mikroorganismen } & \multicolumn{4}{|c|}{ Borsäure-Zusatz } \\
\hline & & $5 \mathrm{pCt}$ & $2,5 \mathrm{pCt}$ & $1 \mathrm{pCt}$. & $1 / 2 \mathrm{pCt}$. \\
\hline $\begin{array}{l}1 . \\
2 . \\
3 . \\
4 . \\
5 .\end{array}$ & 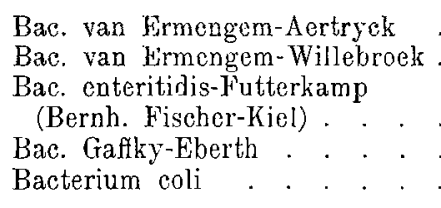 & $\begin{array}{l}+1+ \\
+t+ \\
++t \\
+t \\
+t+\end{array}$ & $\begin{array}{l}\text { tt } \\
\text { tht } \\
+t+ \\
+t+ \\
t+t\end{array}$ & $\begin{array}{l}+4 t \\
+4 t \\
+t+ \\
+t+ \\
+1+\end{array}$ & $\begin{array}{l}\text { th } \\
+t+ \\
+t+ \\
+t+ \\
+t+\end{array}$ \\
\hline
\end{tabular}

$1+\uparrow$ Reichliche Entwickelung wie in der Controle.

Demnach übt Borsäure bei einer Verwendung im Verhältniss von 5 pCt., auch nach mehrtägiger Einwirkung, keine keimtödtenden Eigenschaften auf die zu den Versuchen verwendeten Bacterien aus. 
116 R. Bassenge, Ueber die Wirkung der Borsäure auf einige Bakterien etc.

Endlich wurden noch in ähnlicher Weise Versuche mit Bacillus botulinus angestellt. Als Nährboden wurde 2 proc. Traubenzuckerbouillon benutzt, in welcher der Bacillus botulinus sich reiclılich entwickelte. Auch bei diesen Versuchen war das Ergebniss ein ähnliches, indem durch 2,5 Procentgehalt an Borsäure im Nährboden die Entwickelung nicht mehr gehemmt wurde und in dem Zusatz von 5 pCt. Borsäure zu einer Cultur diese nicht völlig zu vernichten vermochte.

Die Borsäure löste sich in der Nährbouillon nur in geringen Mengen (1-2 pCt.) leicht. In stärkeren Concentrationen war hierzu Erhitzen im Dampftopf nöthig; bis 8 pCt. Borsäure blieb nach der Lösung in hoher Temperatur dann auch beim Abkühlen auf $20^{\circ} \mathrm{C}$. gelöst. Die Entwickelungshemmungs-Versuche in den auf $20^{\circ} \mathrm{C}$. abgekühlten Bouillonröhrchen boten nicht die geringsten Schwierigkeiten. Bei den Abtödtungsversuchen der voll entwickelten Culturen mussten die Borsäurezusätze durch entsprechend concentrirte Borsäure-Lösungen in Bouillon geschehen. In den mit 5 pCt. Borsäure versetzten Culturen fiel dann meist ein kleiner Theil der Borsäure in Substanz aus. Das Endergebniss der Versuche wird jedenfalls durch diesen kleinen Fehler nicht geändert, da höhere Zusätze als 2 pCt. Borsäure zu Nahrungsmitteln auch von den Anhängern der Borsäureverwendung weder für nöthig, noch für zulässig gehalten werden.

Die Versuche haben aber ergeben, dass die hier besonders in Betracht gezogenen Bacterien des Fleisch- und Wurstgiftes durch einen Zusatz von 2 pCt. Borsäure weder in der Entwickelung gehemmt, noch viel weniger dadurch abgetödtet werden. Somit hat der Borsäurezusatz zu Nahrungsmitteln zur Befreiung derselben von pathogenen, für Menschen besonders gefährlichen Mikroorganismen nicht den geringsten Zweck. Ein durch derartige Bacterien inficirtes Fleischpräparat würde nichts von seiner Gefährlichkeit für die menschliche Gesundheit einbüssen, während die conservirenden Eigenschaften der Borsäure die Zersetzung durch die weniger widerstandsfähigen Fäulnissbacterien verhindern und so der an sich gesundheitsschädlichen vergifteten Nahrung das Aussehen einer gut erhaltenen oder frischen Fleischconserve verleihen würde. Aus diesem Grunde berechtigen die vorstehend mitgetheilten Versuche zu dem Schluss, dass die Conservirung von animalischen Nahrungsmitteln mittelst Borsäure für den reellen Fabrikanten praktisch keinen Nutzen bietet, für den Consumenten aber in Folge der Unwirksamkeit der Borsäure auf die genannten pathogenen Bacterien eine schwere Gefahr in sich schliesst. 